\title{
A PROCEDURE FOR EVALUATING THE SOIL-STRUCTURE INTERACTION EFFECTS ON THE SYSTEM PERIOD AND DAMPING OF PILE-SUPPORTED STRUCTURES
}

\author{
Cristina Medina ${ }^{1}$, Juan J. Aznárez, Luis A. Padrón, and Orlando Maeso \\ Instituto Universitario de Sistemas Inteligentes y Aplicaciones Numéricas en Ingeniería (SIANI). \\ Universidad de Las Palmas de Gran Canaria \\ Edificio Central del Parque Científico y Tecnológico del Campus Universitario de Tafira. Las Palmas \\ de Gran Canaria. España. \\ e-mail: cmedina ${ }^{1}$, jjaznarez, lpadron, omaeso@ siani.es
}

Keywords: soil-structure interaction, piled foundations, effective period, effective damping.

\begin{abstract}
Soil-structure interaction involves kinematic and inertial effects that affect the dynamic behaviour of the structures. Thus, a proper assessment of their dynamic response requires the development of models that incorporate, in a rigorous manner, the interaction between the structure and the soil on which it is founded. These interaction phenomena depend on factors such as: the foundation type, its geometry and embedment depth, the soil type and stratigraphy as well as the characteristics of the structure. In line with other authors' studies for shallow [7] and embedded foundations [15], a simple substructuring model of soil-structure interaction in the frequency domain is proposed herein to evaluate the influence of these factors on the dynamic response of structures founded on pile groups when subjected to seismic loads. A BEM-FEM coupling model [5] is used to compute the impedance functions and the kinematic interaction factors. A simple and stable procedure is developed in order to estimate the period and damping of structures supported by different configurations of pile groups considering soil-structure interaction. For this purpose, several modifications are introduced in the strategy presented by Avilés and Pérez-Rocha [15] for embedded foundations. A diagonal impedance matrix that takes into account the cross-coupled impedances of pile groups, which allows getting manageable equations, is obtained in the lines of Maravas et al. [16] in the case of single piles. All equations are expressed in terms of dimensionless parameters. An analysis of the influence of some of the main characteristics of the foundation affecting the system response is accomplished. The results show that cross-coupled impedances and soil-structure interaction effects should not be neglected.
\end{abstract}




\section{INTRODUCTION}

The dynamic characteristics of the interacting system, as well as the ground motion around the foundation, are both influenced by kinematic and inertial effects associated to soil-structure interaction (SSI). The exact analysis of this interaction for building structures may be implemented through a substructuring methodology, which enables, moreover, to accomplish parametric analysis in the broad sense with low computational effort. It is common knowledge that two fundamental problems have to be solved in these models in order to carry out a SSI harmonic analysis: the evaluation of the impedance functions and the input motion (kinematic interaction) of the foundation. Then soil-structure system is analized through a rigid-base structure over springs and dashpots representing the soil-foundation system and subjected to a base excitation due to the kinematic interaction factors obtained for the type of foundation analized.

On the other hand, direct approaches, modelling simultaneously the main aspects of the problem and their mutual interactions more rigorously [1-5], are both more complex and more demanding from the computational point of view, and are consequently not frequently used for the analysis of this kind of problems. Even so, these methods are specially competitive in the analysis of interaction phenomena among nearby structures, and in problems involving nonlinearities.

The effects of SSI on the effective period and damping of soil-structure systems have been extensively studied either for surface-supported foundations (e.g. [6-12]) or for embedded foundations [13, 14]. However, they have been examined at the exclusion of the kinematic interaction. Avilés et al. [15] evaluate the effects of foundation embedment on the effective period and damping and the response of soil-structure systems, considering both kinematic and inertial interaction. Among other simplifying assumptions, all these solutions neglect the cross-coupled stiffness and damping terms.

On the other hand, there are few studies in the scientific literature that analyse the dynamic characteristics of pile-supported structures. In this line, Maravas et al. [16] presented an approximate iterative procedure placing the reference system at a depth such that a diagonal impedance matrix is obtained. This procedure allows to study the SSI effects on single-pile supported onestorey shear structures considering the influence of cross-coupled impedances on their dynamic response.

The aim of this work is to evaluate the influence of SSI on the period and damping of structures founded on square pile groups, in homogeneous viscoelastic half-spaces subjected to vertically incident $\mathrm{S}$ waves. The analysis is performed by a substructuring model in the frequency domain that takes into account both kinematic and inertial interaction effects. In order to do this, a simplified, stable and accurate procedure is proposed herein. This procedure allows to determine the dynamic characteristics of an equivalent viscously damped single-degree-offreedom (SDOF) oscillator, which being subjected to the free-field ground motion, causes the same response in terms of shear force at the base of the structure as the coupled system involving kinematic and inertial interaction with the foundation ground within the range where the peak response occurs.

All equations are expressed in terms of the main dimensionless parameters of the problem which considerably facilitates the analysis of their influence on the system dynamic response.

In this study, the harmonic response of the soil-structure system is computed by making use of impedance functions and kinematic interaction factors, which are both frequency-dependent functions, computed by a BEM-FEM coupling model [5].

Finally, results for different piles configurations are presented. The influence of some of the 
parameters involved (mass density ratio, fixed-base struture damping, pile-soil Young's modulus ratio, number of piles) are studied over practical ranges of interest.

\section{PROBLEM DEFINITION}

A model consisting of a single-degree-of-freedom system in its fixed-base condition, as the one represented in Figure1, is used in this paper to study the dynamic behaviour of linear shear structures. This model may represent either one-storey buildings or one mode of vibration of multi-storey multi-mode structures. The structure is considered to be founded on a square pile group embedded in a homogeneous, viscoelastic and isotropic half-space. The pile cap that constrains the pile heads is assumed to be a rigid square plate of negligible thickness which is not in contact with the half-space. The columns of the structure are supposed to be massless and axially inextensible. Both the foundations mass and the structural mass are considered to be uniformly distributed over square areas. The pile group configuration, which is illustrated in Figure 1, is defined by foundation halfwidth $b$, centre-to-centre spacing between adjacent piles $s$, length $L$ and sectional diameter $d$ of piles, cap mass $m_{o}$ and cap moment of inertia about a horizontal axis passing through the centre of gravity of the cap $I_{o}$. The dynamic behaviour of the structure can be defined by its fixed-base fundamental period $T$, the height $h$ of the resultant of the inertia forces for the first mode, the mass $m$ participating in this mode, the moment of inertia of the vibrating mass $I$, the structural stiffness $k$, and the viscous damping ratio $\xi$.
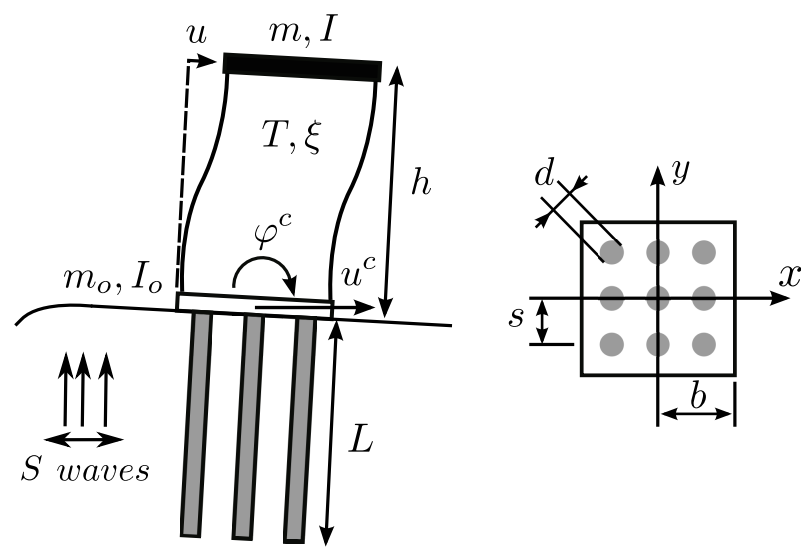

Figure 1: Problem definition.

The system response, when soil-structure interaction is considered, can be approximated by that of a three-degree-of-freedom system defined by the structural horizontal deflection $u$ together with the foundation horizontal displacement $u^{c}$ and rocking $\varphi^{c}$. Vertical and torsional motions are neglected in this study.

\section{SUBSTRUCTURE MODEL}

This problem can be studied using the substructure methodology which provides accurate results for this kind of problems and at the same time allows performing parametric analysis with very little computational effort. For this purpose the system is subdivided into soilfoundation stiffness and damping, represented by means of springs and dashpots (see Figure 2), and building-cap superstructure. The solution can be broken into three steps, as proposed by Kausel and Roësset [17]. In the case under study, the first step consist in the determination of 
the frequency dependent kinematic interaction factors which represent the horizontal $\left(u_{g}\right)$ and rocking $\left(\varphi_{g}\right)$ motions of the massless pile cap when subjected to the same input motion as the total solution. In the present case of deep foundations, even vertically incident $S$ waves in a halfspace (for which the free-field motion at the ground surface is exclusively horizontal) generate rocking kinematic response at the pile cap. The second step is to obtain the impedances whose mathematical representation is $K_{i j}=k_{i j}+\mathrm{i} a_{o} c_{i j}$. The dimensionless frequency is defined as $a_{o}=\omega b / c_{s}$; where $\omega$ is the excitation circular frequency, $c_{s}=\sqrt{\mu_{s} / \rho_{s}}$ the speed of propagation of shear waves in the halfspace, and $\rho_{s}$ and $\mu_{s}$ the soil mass density and shear modulus of elasticity, respectively. These complex-valued frequency-dependent functions $\left(k_{x x}, c_{x x}\right),\left(k_{\theta \theta}, c_{\theta \theta}\right)$ and $\left(k_{x \theta}, c_{x \theta}\right)$ represent the stiffness and damping of the soil in the horizontal, rocking and cross-coupled horizontal-rocking vibration modes,respectively. When computed numerically, the cross-coupled terms $\left(k_{x \theta}, c_{x \theta}\right)$ and $\left(k_{\theta x}, c_{\theta x}\right)$, which should be identical, are not exactly equal to one another. Given that this difference is not significant for practical purposes, they are considered identical in this approach. Lastly, the response of the structure supported on springs and subjected to the motion computed in the first step is computed at each frequency.

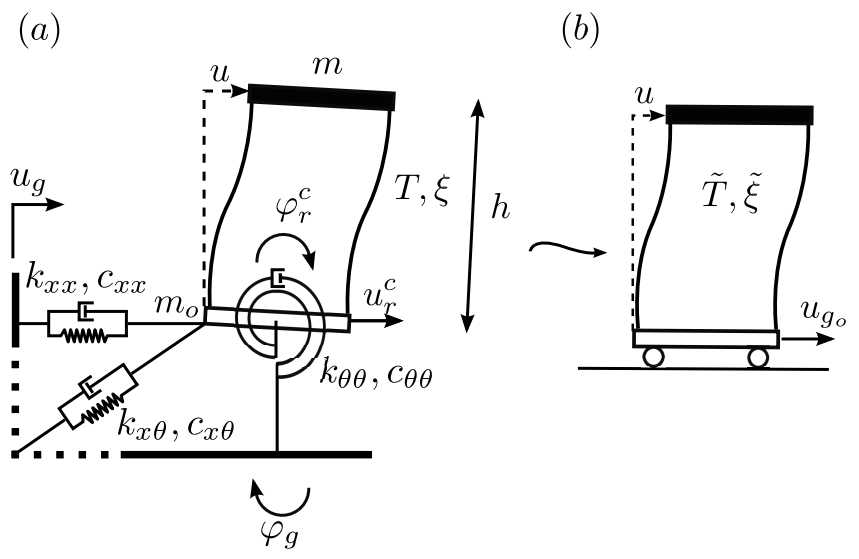

Figure 2: (a) Substructure model of a one-storey structure. (b) Equivalent single-degree-offreedom oscillator

Hence, the equations of motion of the system depicted in Figure 2(a), assuming small displacements, can be expressed in terms of relative motions, as

$$
\begin{gathered}
m \cdot\left[\ddot{u}+\ddot{u}_{r}^{c}+\ddot{u}_{g}+h\left(\ddot{\varphi}_{g}+\ddot{\varphi}_{r}^{c}\right)\right]+K \cdot u=0 \\
m_{o} \cdot\left[\ddot{u}_{r}^{c}+\ddot{u}_{g}\right]+K_{x x} \cdot u_{r}^{c}+K_{x \theta} \cdot \varphi_{r}^{c}-K \cdot u=0 \\
m \cdot h\left[\ddot{u}+\ddot{u}_{r}^{c}+\ddot{u}_{g}+h\left(\ddot{\varphi}_{g}+\ddot{\varphi}_{r}^{c}\right)\right]+I\left(\ddot{\varphi}_{r}^{c}+\ddot{\varphi}_{g}\right) \\
+K_{\theta x} \cdot u_{r}^{c}+K_{\theta \theta} \cdot \varphi_{r}^{c}+I_{o}\left(\ddot{\varphi}_{r}^{c}+\ddot{\varphi}_{g}\right)=0
\end{gathered}
$$

where eq. (1) represents the horizontal force equilibrium of the structure, eq. (2) the horizontal force equilibrium of the soil-foundation system and eq. (3) the moment equilibrium of the 
structure-foundation system about the centre of gravity of the pile cap. This set of equations can be expressed in a matrix form as

$$
\begin{gathered}
\left\{\left[\begin{array}{ccc}
K & 0 & 0 \\
-K & K_{x x} & K_{x \theta} \\
0 & K_{\theta x} & K_{\theta \theta}
\end{array}\right]-\omega^{2}\left[\begin{array}{ccc}
m & m & m h \\
0 & m_{o} & 0 \\
m h & m h & m h^{2}+I_{o}+I
\end{array}\right]\right\} \\
{\left[\begin{array}{c}
u \\
u_{r}^{c} \\
\varphi_{r}^{c}
\end{array}\right]=\omega^{2}\left\{\left[\begin{array}{c}
m \\
m_{o} \\
m h
\end{array}\right] u_{g}+\left[\begin{array}{c}
m h \\
0 \\
m h^{2}+I_{o}+I
\end{array}\right] \varphi_{g}\right\}}
\end{gathered}
$$

where $K=k+\mathrm{i} 2 \omega_{n} m \xi \omega$, being $\omega_{n}=2 \pi / T$ the fixed-base natural frequency of the superstructure, and motions have been assumed to be time-harmonic of the type $u(t)=u e^{i \omega t}$. Once the foundation input motion is computed and the right-hand vector and the coefficient matrix are known, the structural deflection and foundation relative motions can be computed for every frequency.

\section{DIMENSIONLESS PARAMETERS}

A set of dimensionless parameters, covering the main features of SSI problems, has been repeatedly used in the related literature to perform parametric analyses [7, 8, 13, 15]. Following these authors, the parameters that will be used herein to characterize the soil-foundationstructure system are:

- The wave parameter $\sigma=c_{s} T / h$, measuring the soil-structure relative stiffness.

- The structural slenderness ratio $h / b$, measuring the relation between structure height and foundation half-width.

- The mass density ratio $\delta=m /\left(4 \rho_{s} b^{2} h\right)$ between structure and supporting soil.

- The foundation-structure mass ratio $m_{o} / m$.

- The dimensionless fixed-base natural frequency of the structure, that can be expressed by means of the ratio $\lambda=\omega_{n} / \omega$.

- The fixed-base structure damping ratio $\xi$.

- The dimensionless excitation frequency $a_{o}=\omega b / c_{s}=(b / d)\left(\omega d / c_{s}\right)$.

- The Poisson's ratio $\nu_{s}$ and damping ratio $\xi_{s}$ of the soil.

On the other hand, the following dimensionless parameters are considered regarding the pile foundations:

- The pile spacing ratio $s / d$, expressed as the ratio between the centre-to-centre spacing between adjacent piles and their sectional diameter.

- The embedment ratio $L / b$, measuring the relation between pile length and foundation half-width. 
- The pile slenderness ratio $L / d$, measuring the relation between length and sectional diameter of piles.

- The pile-soil Young's modulus ratio $E_{p} / E_{s}$, measuring the pile-soil relative stiffness.

- The soil-pile densities ratio $\rho_{s} / \rho_{p}$.

- The size of the square pile group.

- The dimensionless frequency $a_{o}$.

\section{DIMENSIONLESS SYSTEM EQUATIONS}

It can be shown that the equation of motion of the system (eq. (41) can be expressed as a function of the dimensionless parameters already defined, as follows

$$
\begin{aligned}
& \left\{\begin{array}{ccc}
\lambda^{2}+2 \lambda \xi \mathrm{i} & 0 & 0 \\
0 & \lambda^{2} \sigma^{2} \frac{1}{16 \pi^{2}} \frac{h}{b} \frac{1}{\delta} \tilde{K}_{x x} & \lambda^{2} \sigma^{2} \frac{1}{\delta} \frac{1}{16 \pi^{2}} \tilde{K}_{x \theta} \\
0 & \lambda^{2} \sigma^{2} \frac{1}{\delta} \frac{1}{16 \pi^{2}} \tilde{K}_{\theta x} & \lambda^{2} \sigma^{2} \frac{1}{16 \pi^{2}} \frac{b}{h} \frac{1}{\delta} \tilde{K}_{\theta \theta}
\end{array}\right] \\
& \left.-\left[\begin{array}{ccc}
1 & 1 & 1 \\
1 & 1+\frac{m_{o}}{m} & 1 \\
1 & 1 & 1+\frac{b^{2}}{3 h^{2}}\left(1+\frac{m_{o}}{m}\right)
\end{array}\right]\right\}\left[\begin{array}{c}
\omega_{n}^{2} u / \omega^{2} u_{g_{o}} \\
\omega_{n}^{2} u_{r}^{c} / \omega^{2} u_{g_{o}} \\
\omega_{n}^{2} h \varphi_{r}^{c} / \omega^{2} u_{g_{o}}
\end{array}\right]= \\
& -\lambda^{2}\left\{\left[\begin{array}{c}
1 \\
1+\frac{m_{o}}{m} \\
1
\end{array}\right] I_{u}+\frac{h}{b}\left[\begin{array}{c}
1 \\
1+\frac{b^{2}}{3 h^{2}}\left(1+\frac{m_{o}}{m}\right)
\end{array}\right] I_{\varphi}\right\}
\end{aligned}
$$

Equation (5) is obtained by introducing the structural stiffness and damping expressions, that corresponds to a viscous damping model, into the equation (4); adding the two firsts rows of the equation so that the second equation represents the horizontal balance of the whole; replacing the structural stiffness by its expression $k=\omega_{n}^{2} m$; extracting the structural mass $m$, as a common factor, from both sides of the equation and adding the matrices of the first term of the equation; extracting $\omega^{2} / \omega_{n}^{2}$ as a common factor from de first term of the equation; dividing by $h$ the third row of the equation and the third column of the system matrix; replacing the rotational inertias $I_{o}$ and $I$ by their expressions $I_{o}=m_{o} b^{2} / 3$ and $I=m b^{2} / 3$, respectively; normalizing the kinematic interaction factors and the impedance functions; and expressing the later ones in a dimensionless form.

The impedance functions are normalized as follows: $\tilde{K}_{x x}=K_{x x} / \mu_{s} b, \tilde{K}_{\theta \theta}=K_{\theta \theta} / \mu_{s} b^{3}$ and $\tilde{K}_{x \theta}=K_{x \theta} / \mu_{s} b^{2}$, and the kinematic interaction factors are normalized with the free-field motion at the surface $u_{g_{o}}$, being $I_{u}=u_{g} / u_{g_{o}}$ and $I_{\varphi}=\varphi_{g} b / u_{g_{o}}$, both being functions of the dimensionless frequency $a_{o}$.

Negligible differences were obtained from the comparison between the results computed by using this model and those reported by Veletsos [7] for shallow foundations, and Avilés and Pérez-Rocha [15] for embedded foundations.

\section{SOLUTION STRATEGIES}

The objective is to find the dynamic characteristics of an equivalent viscously damped singledegree-of-freedom (SDOF) oscillator, as that shown in Fig. 2 (b), which being subjected to the free-field ground motion, causes the same response in terms of shear force at the base of the 
structure as the coupled system involving kinematic and inertial interaction with the foundation ground within the range where the peak response occurs. This SDOF system can be defined by its undamped natural period $\tilde{T}$ and its damping ratio $\tilde{\xi}$.

A procedure based on finding the eigenvalue $\tilde{\lambda}$ of the 3DOF system is proposed in this paper to determine the dynamic characteristics of the equivalent SDOF system. This procedure is similar to that proposed by Avilés and Pérez-Rocha [15] for embedded foundations. However, contrary to what they do, herein the cross-coupled horizontal-rocking terms and the high-order terms involving products of damping coefficients are considered. Neglecting the cross-coupled stiffness and damping terms $k_{x \theta}$ and $c_{x \theta}$ is not acceptable for pile foundations, not even for certain configurations of embedded foundations, even though such assumption has been extensively used by many authors [6-14].

In order to obtain manageable approximated expressions for the period and damping of the interacting system while keeping all the impedances, the soil-foundation interaction is condensed to a point at a certain virtual depth $D(\omega)=-K_{x \theta} / K_{x x}$ (see Figure 3) such that the impedance matrix becomes diagonal, as some authors propose [16, 18]. If, in addition, $m_{o}, I$ and $I_{o}$ are neglected as usual (see, for instance [15]), eq. (5]) becomes

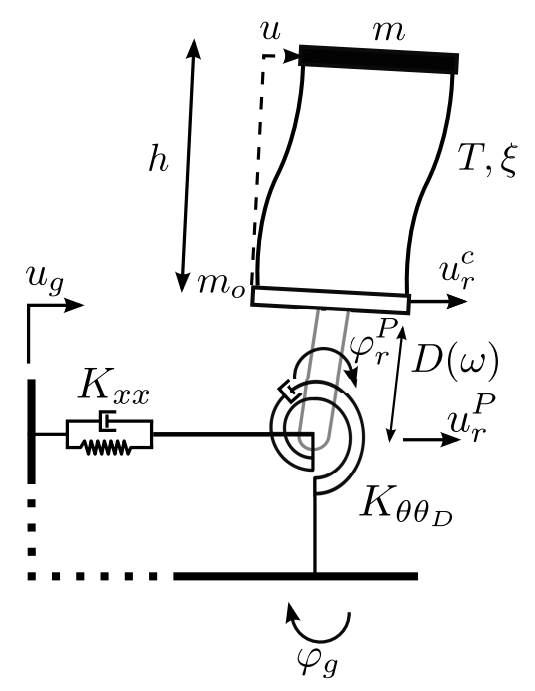

Figure 3: Equivalent model with diagonalized impedance matrix

$$
\begin{aligned}
& \left\{\lambda^{2}\left[\begin{array}{ccc}
\left(1+\mathrm{i} 2 \xi^{\prime}\right) & 0 & 0 \\
0 & \alpha_{x x}^{2}\left(1+\mathrm{i} 2 \xi_{x x}\right) & 0 \\
0 & 0 & \alpha_{\theta \theta}^{2}\left(1+\mathrm{i} 2 \xi_{\theta \theta}\right)
\end{array}\right]-\right. \\
& \left.\left[\begin{array}{lll}
1 & 1 & 1 \\
1 & 1 & 1 \\
1 & 1 & 1
\end{array}\right]\right\} \cdot\left[\begin{array}{c}
\omega_{n}^{2} u / \omega^{2} u_{g_{o}} \\
\omega_{n}^{2} u_{r}^{P} / \omega^{2} u_{g_{o}} \\
\omega_{n}^{2}(h+D) \varphi_{r}^{c} / \omega^{2} u_{g_{o}}
\end{array}\right]=-\lambda^{2}\left(I_{u}+\frac{h}{b} I_{\varphi}\right)\left[\begin{array}{l}
1 \\
1 \\
1
\end{array}\right]
\end{aligned}
$$

where,

$$
\begin{gathered}
\xi^{\prime}=\frac{\omega}{\omega_{n}} \xi \\
\alpha_{x x}^{2}=\sigma^{2} \frac{1}{16 \pi^{2}} \frac{h}{b} \frac{1}{\delta} \tilde{k}_{x x}
\end{gathered}
$$




$$
\begin{gathered}
\xi_{x x}=\frac{\tilde{c_{x x}}}{2 \tilde{k_{x x}}} \\
\alpha_{\theta \theta}^{2}=\sigma^{2} \frac{1}{16 \pi^{2}} \frac{h}{b} \frac{1}{\delta} \operatorname{Re}\left[\frac{b^{2}}{(h+D)^{2}} \tilde{K}_{\theta \theta_{D}}\right] \\
\xi_{\theta \theta}=\frac{\operatorname{Im}\left[\frac{b^{2}}{(h+D)^{2}} \tilde{K}_{\theta \theta_{D}}\right]}{2 \operatorname{Re}\left[\frac{b^{2}}{(h+D)^{2}} \tilde{K}_{\theta \theta_{D}}\right]}
\end{gathered}
$$

being $\tilde{K}_{x x}=\tilde{k}_{x x}+\mathrm{i} \tilde{c}_{x x}$ and

$$
\begin{gathered}
\tilde{K}_{\theta \theta_{D}}=\frac{1}{\mu_{s} b^{3}}\left(K_{\theta \theta}-\frac{K_{\theta x}^{2}}{K_{x x}}\right) \\
\frac{b^{2}}{(h+D)^{2}}=\left(\left(\frac{h}{b}\right)^{2}-2\left(\frac{h}{b}\right) \frac{\tilde{K}_{\theta x}}{\tilde{K}_{x x}}+\left(\frac{\tilde{K}_{\theta x}}{\tilde{K}_{x x}}\right)^{2}\right)^{-1}
\end{gathered}
$$

Solving the complex system of algebraic equations given in (6) for $\omega_{n}^{2} u / \ddot{u}_{g_{o}}$ yields the following expression for $Q$, which represents the ratio of the shear force at the base of the structure to the effective earthquake force [19].

$$
Q(\lambda)=\left|\frac{I_{u}(\lambda)+\frac{h}{b} I_{\varphi}(\lambda)}{A(\lambda)+\mathrm{i} B(\lambda)}\right|
$$

where

$$
\begin{aligned}
& A(\lambda)=1-\frac{1}{\lambda^{2}}-\frac{1+4 \xi_{x x} \xi^{\prime}}{\lambda^{2} \alpha_{x x}^{2}\left(1+4 \xi_{x x}^{2}\right)}-\frac{1+4 \xi_{\theta \theta} \xi^{\prime}}{\lambda^{2} \alpha_{\theta \theta}^{2}\left(1+4 \xi_{\theta \theta}^{2}\right)} \\
& B(\lambda)=2\left[\xi^{\prime}-\frac{\xi^{\prime}-\xi_{x x}}{\lambda^{2} \alpha_{x x}^{2}\left(1+4 \xi_{x x}^{2}\right)}-\frac{\xi^{\prime}-\xi_{\theta \theta}}{\lambda^{2} \alpha_{\theta \theta}^{2}\left(1+4 \xi_{\theta \theta}^{2}\right)}\right]
\end{aligned}
$$

The first root $\lambda^{\prime}$ of equation (15) leads to a SDOF system whose peak response does not always lead to an acceptable approximation for the 3DOF system peak response. However, better resuts are obtained by neglecting all second-order damping terms, which leads to the following approximate expression for $A$

$$
A(\lambda)=1-\frac{1}{\lambda^{2}}-\frac{1}{\lambda^{2} \alpha_{x x}^{2}}-\frac{1}{\lambda^{2} \alpha_{\theta \theta}^{2}}
$$

The dimensionless undamped natural frequency of the SDOF system $\tilde{\lambda}=\omega_{n} / \tilde{\omega}_{n}$ can be found as the root of the equation (17). This is equivalent to the resolution of the eigenvalue problem from equation (6), without considering damping. 
As, in this case, $\tilde{\xi}=1 /(2 Q(\tilde{\lambda}))$, and taking the expression for $Q(\tilde{\lambda})$ obtained from taking equations (15) and (16) as values of $A$ and $B$, the effective damping ratio $\tilde{\xi}$ can be written as follows

$$
\tilde{\xi}=\left|\left(I_{u}+\frac{h}{b} I_{\varphi}\right)^{-1}\left[\frac{\xi^{\prime}}{\tilde{\lambda}^{2}}+\frac{1}{\tilde{\lambda}^{2}}\left(\frac{\xi_{x x}}{\alpha_{x x}^{2}\left(1+\mathrm{i} 2 \xi_{x x}\right)}+\frac{\xi_{\theta \theta}}{\alpha_{\theta \theta}^{2}\left(1+\mathrm{i} 2 \xi_{\theta \theta}\right)}\right)\right]\right|
$$

The obtained values of the dynamic characteristics, effective system period $\tilde{T}$ and damping $\tilde{\xi}$, are used to build modified response spectra that include SSI effect which allow to obtain more accurate design criteria for building structures.

\section{RESULTS}

Herein, the described procedure is applied to several configurations of pile supported structures in order to perform parametric studies of the influence of SSI effects on their dynamic response. In this paper, some conclusions are drawn from analysing the influence of the variation of parameters such as the size of the pile group, the fixed-base structure damping ratio $\xi$, the mass density ratio $\delta$, the pile-soil Young's modulus ratio $E_{p} / E_{s}$, the wave parameter $\sigma$ and the structural slenderness ratio $h / b$.

Different pile group configurations, for which the values of the dimensionless parameters are listed in Table 1, are analysed. All configurations follow the pattern represented in Figure 4.

Table 1: Pile groups configurations

\begin{tabular}{ccccc}
\hline \multirow{2}{*}{$L / b$} & \multirow{2}{*}{$L / d$} & \multicolumn{3}{c}{$s / d$} \\
\cline { 3 - 5 } & & $2 \times 2$ & $3 \times 3$ & $4 \times 4$ \\
\hline \multirow{2}{*}{1} & 7.5 & 7.5 & 5 & 3.75 \\
& 15 & 15 & 10 & 7.5 \\
\hline \multirow{2}{*}{2} & 7.5 & 3.75 & 2.5 & 1.875 \\
& 15 & 7.5 & 5 & 3.75 \\
& 30 & 15 & 10 & 7.5 \\
\hline \multirow{2}{*}{4} & 15 & 3.75 & 2.5 & 1.875 \\
& 30 & 7.5 & 5 & 3.75 \\
\hline
\end{tabular}

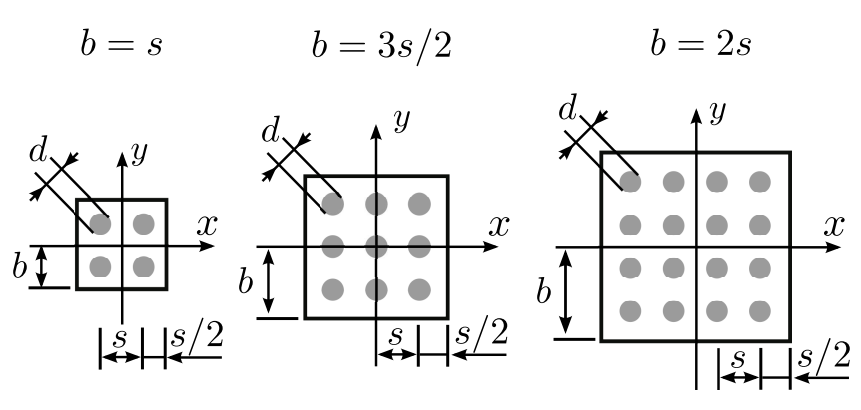

Figure 4: Geometric configuration of groups of $2 \times 2,3 \times 3$ and $4 \times 4$ piles

It is assumed that $m_{o} / m=0 ; \xi=0.05 ; \xi_{s}=0.05$ and $\nu_{s}=0.4$. These values are representative for typical buildings and soils [15]. Moreover $\rho_{s} / \rho_{p}=0.7$. 


\subsection{Impedances and kinematic interaction factors}

In this paper, all impedance functions and kinematic interaction factors are computed using a boundary element (BEM)- finite element (FEM) coupling model [5]. Piles are modelled directly using FEM as beams according to the Bernoulli hypothesis, while soil is modelled using BEM as a linear, isotropic, homogeneous, viscoelastic medium. Welded boundary contact conditions at the pile-soil interfaces are assumed and the pile heads are constrained by a rigid pile-cap which is not in contact with the half-space.

Figures 11 to 15 show the impedances of the pile groups under investigation. On the other hand, Figures 12 to 16 present their kinematic interaction factors (see appendix).

\subsection{Influence of the mass density ratio $\delta$}

Figure 5 illustrates the relevant influence that the mass density ratio between structure and supporting soil has on the system response. This response can be represented in terms of effective period $\tilde{T} / T$ and damping $\tilde{\xi}$ and maximum shear force at the base of the structure per effective earthquake force unit $Q_{m}=\operatorname{Max}\left[\left|\omega_{n}^{2} u / \omega^{2} u_{g_{o}}\right|\right]$. An increase of $\delta$ implies a decrease of the system stiffness which results in greater values of $\tilde{T} / T$ and $\tilde{\xi}$. Thus, lower values of $Q_{m}$ are achieved. The influence of the aforementioned effects becomes more remarkable for increasing values of $h / b$. For the results provided below, the value of this parameter is taken as $\delta=0.15$ because it is representative for typical buildings and soils and has been used in previous works (e.g. [7, 15]).

\subsection{Influence of the fixed-base structure damping ratio $\xi$}

Figure 6 shows how the variation of the fixed-base structure damping ratio influences the effects of SSI on the system dynamic response. It can be observed that this parameter has no influence on the system effective period $\tilde{T} / T$. However, as it is expected, it affects to the system effective damping $\tilde{\xi}$ that reaches greater values as $\xi$ increases. This effect becomes more remarkable for greater values of the wave parameter $\sigma$. By contrast, its influence is negligible when $1 / \sigma \geq 0.4$. These variations on the system effective damping leads to increasing values of $Q_{m}$ for decreasing values of the fixed-base structure damping ratio $\xi$. Furthermore, greater values of the structural slenderness ratio $h / b$ implies a wider range of the parameter $\sigma$ where the variation of $\xi$ has a significant influence.

For the results provided in this paper, the value of this parameter is taken as $\xi=0.05$ because it is representative for typical buildings and has been used in previous works (e.g. [7, 15]).

\subsection{Influence of the pile-soil Young's modulus ratio $E_{p} / E_{s}$}

As it can be seen in Figures 17 to 22, the variation of the pile-soil Young's modulus ratio affects to impedance functions and kinematic interaction factors. Consequently, SSI effects on the system dynamic response are also influenced.

In order to analyse the influence of $E_{p} / E_{s}$ on the dynamic characteristics of the system, Figure 7 presents the results considering two different values of this parameter.

Considering constant properties for the material of piles, lower values of $E_{p} / E_{s}$ imply an increase of the soil stiffness which leads to greater values of the system effective period $\tilde{T} / T$ and lower values of the effective damping $\tilde{\xi}$. Consequently, higher values of $Q_{m}$ are reached. This effect is more remarkable for greater values of the pile slenderness ratio $L / d$. 

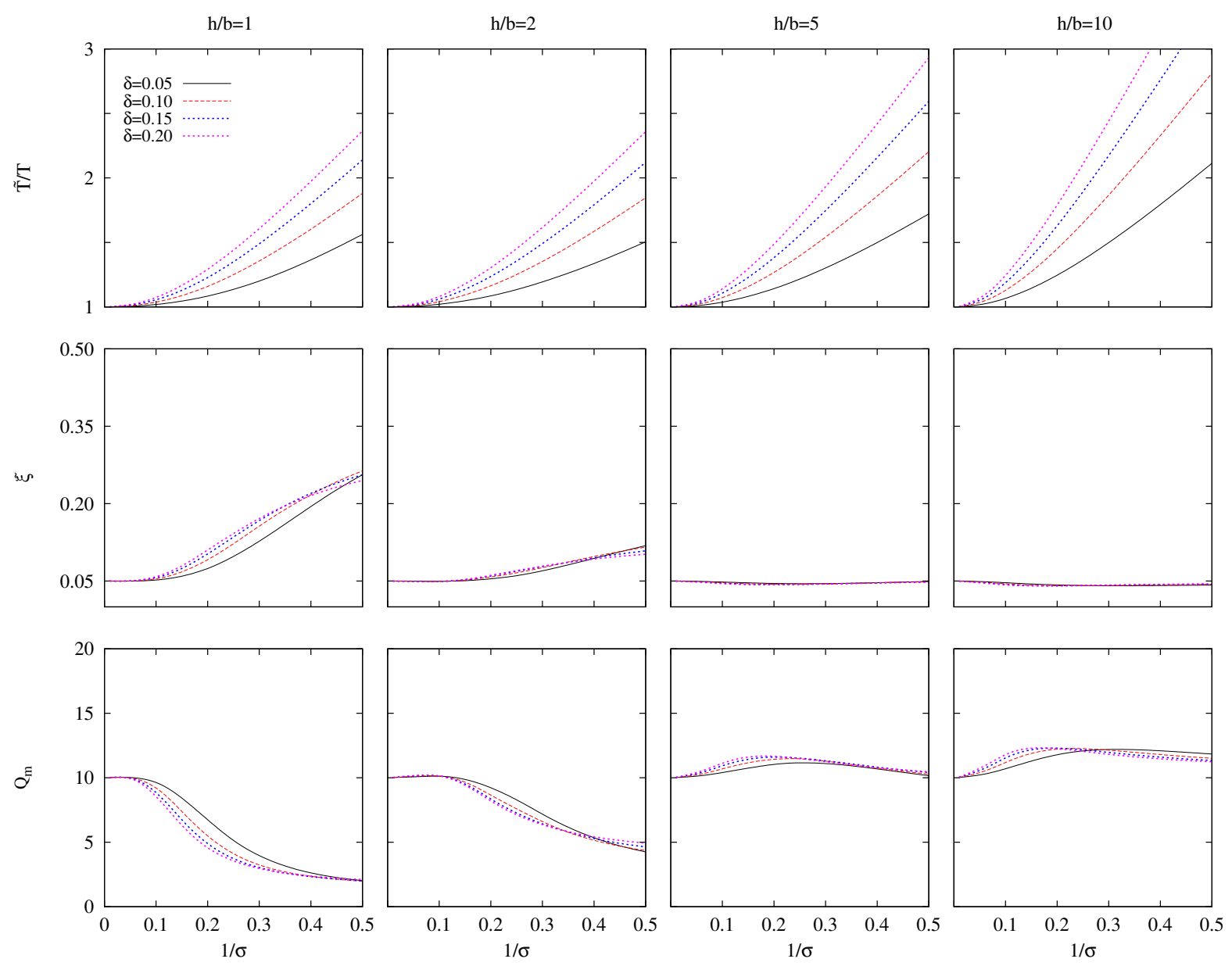

Figure 5: Effective period $\tilde{T} / T$, damping ratio $\tilde{\xi}$ and maximum structural response value $Q_{m}$ for a $3 \times 3$ pile group with $L / d=7.5, L / b=1, \xi=0.05, E p / E s=10^{3}$ and $\xi_{s}=0.05$. Influence of the mass density ratio $\delta$ 

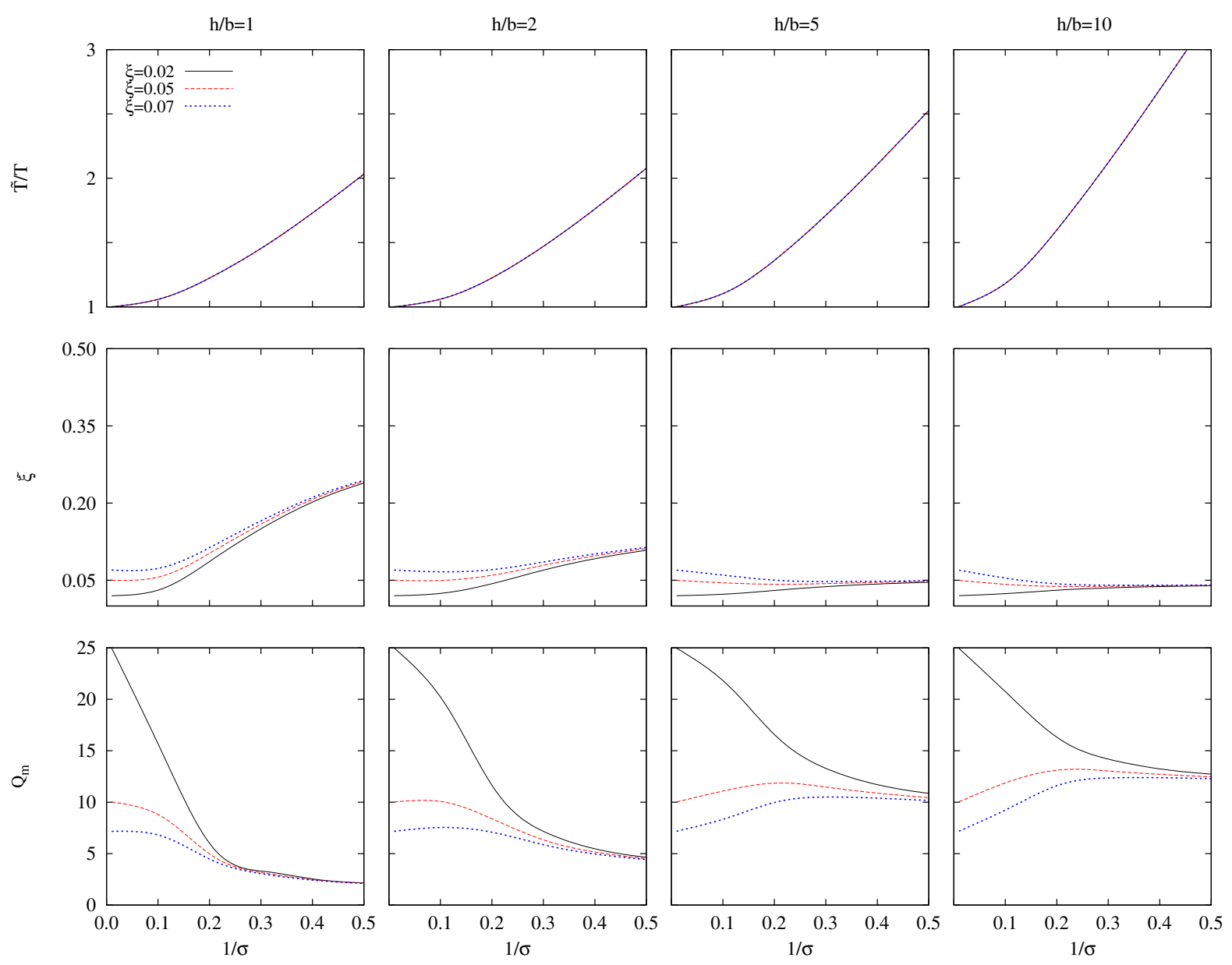

Figure 6: Effective period $\tilde{T} / T$, damping ratio $\tilde{\xi}$ and maximum structural response value $Q_{m}$ for a $3 \times 3$ pile group with $L / d=30, L / b=2, \delta=0.15, E p / E s=10^{3}$ and $\xi_{s}=0.05$. Influence of the fixed-base structure damping ratio $\xi$ 

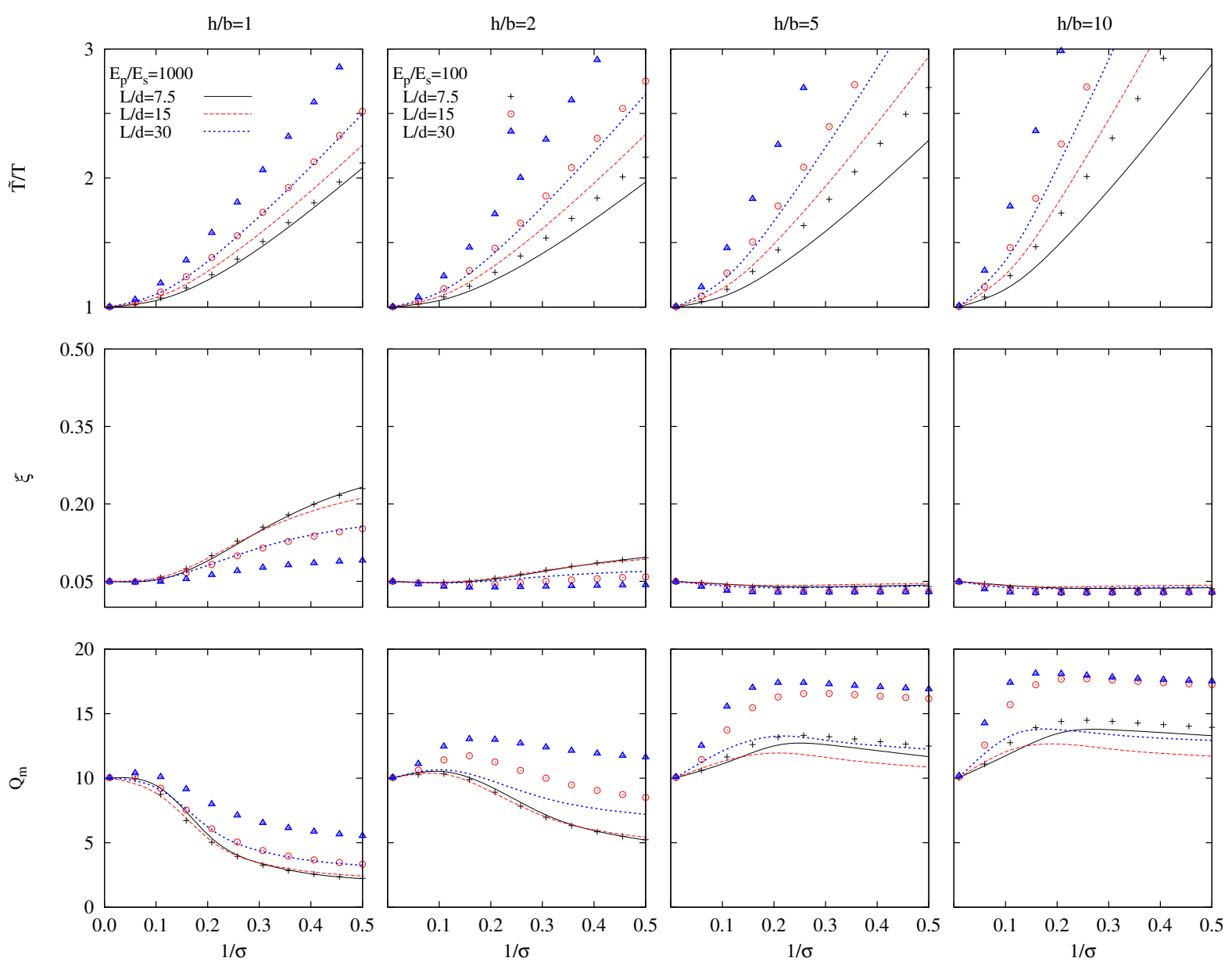

Figure 7: Effective period $\tilde{T} / T$, damping ratio $\tilde{\xi}$ and maximum structural response value $Q_{m}$ for $2 \times 2$ pile groups with $L / b=2, \delta=0.15, \xi=0.05$ and $\xi_{s}=0.05$. Influence of the pile-soil Young's modulus ratio $E_{p} / E_{s}$ 

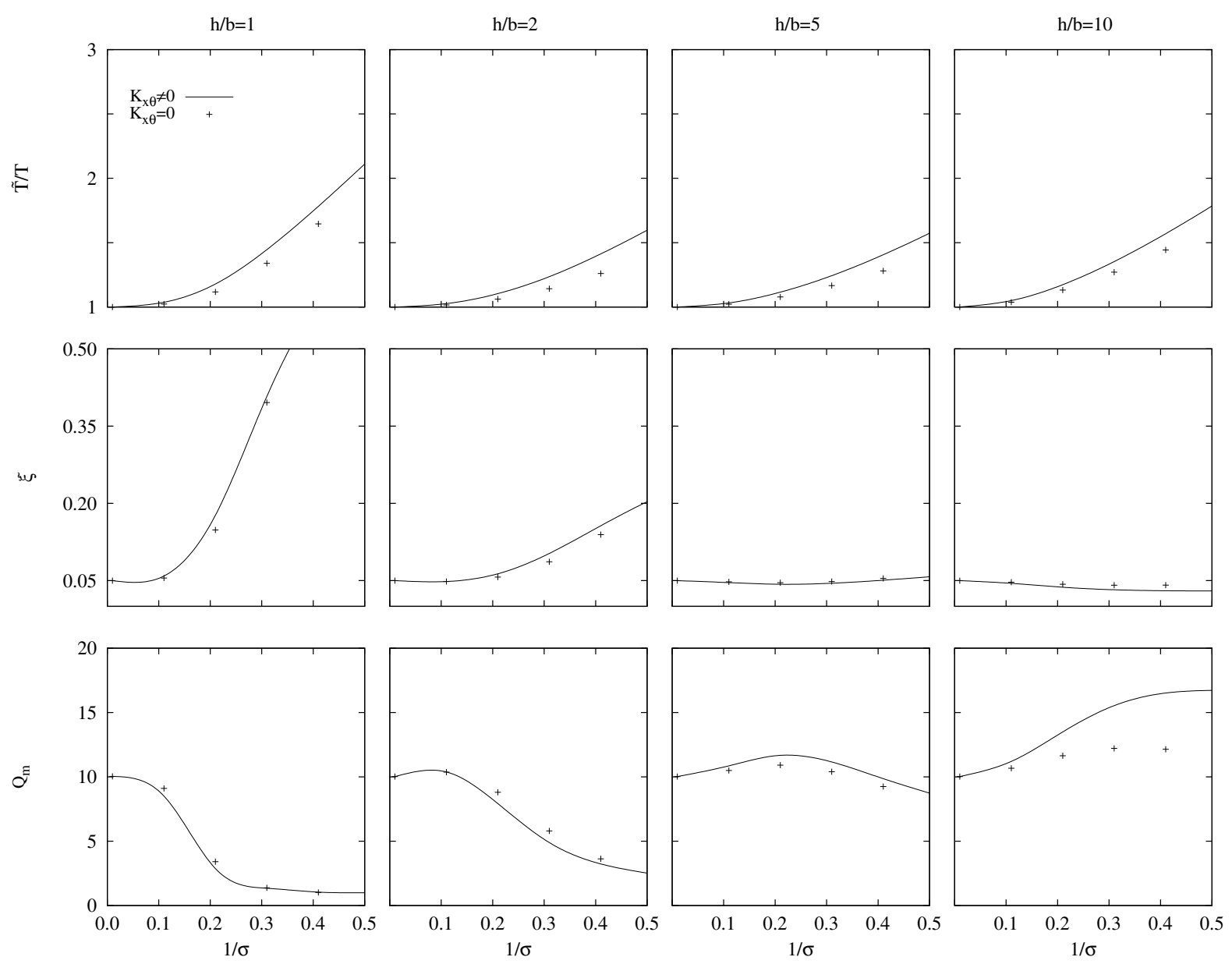

Figure 8: Effective period $\tilde{T} / T$, damping ratio $\tilde{\xi}$ and maximum structural response value $Q_{m}$ for $4 \times 4$ pile groups with $L / d=15, L / b=4$ and $\xi_{s}=0.05$. Influence of cross-coupled impedances

\subsection{Influence of cross-coupled impedances}

Figure 8 illustrates the influence of the cross-coupled impedances on the system dynamic response. As it can be seen, for configurations with $h / b \geq 5$ the system dynamic response in terms of $Q_{m}$ is subestimated when these elements of the matrix of impendances are neglected. The relative error, in terms of $Q_{m}$, committed by neglecting the cross-coupled impedances, could reach a $40 \%$. Therefore, all the results presented in this paper are obtained considering all the elements of the matrix of impedances.

\subsection{Influence of kinematic interaction factors}

In order to show how kinematic interaction influences the system dynamic response, Figure 9 presents the results involving total soil-structure interaction (both kinematic and inertial interaction) or only inertial interaction. The system effective period $\tilde{T} / T$ is not affected by kinematic interaction. However, generally, the effective damping $\tilde{\xi}$ decreases when these factors are considered. Therefore, the results for the system dynamic response computed without taking 

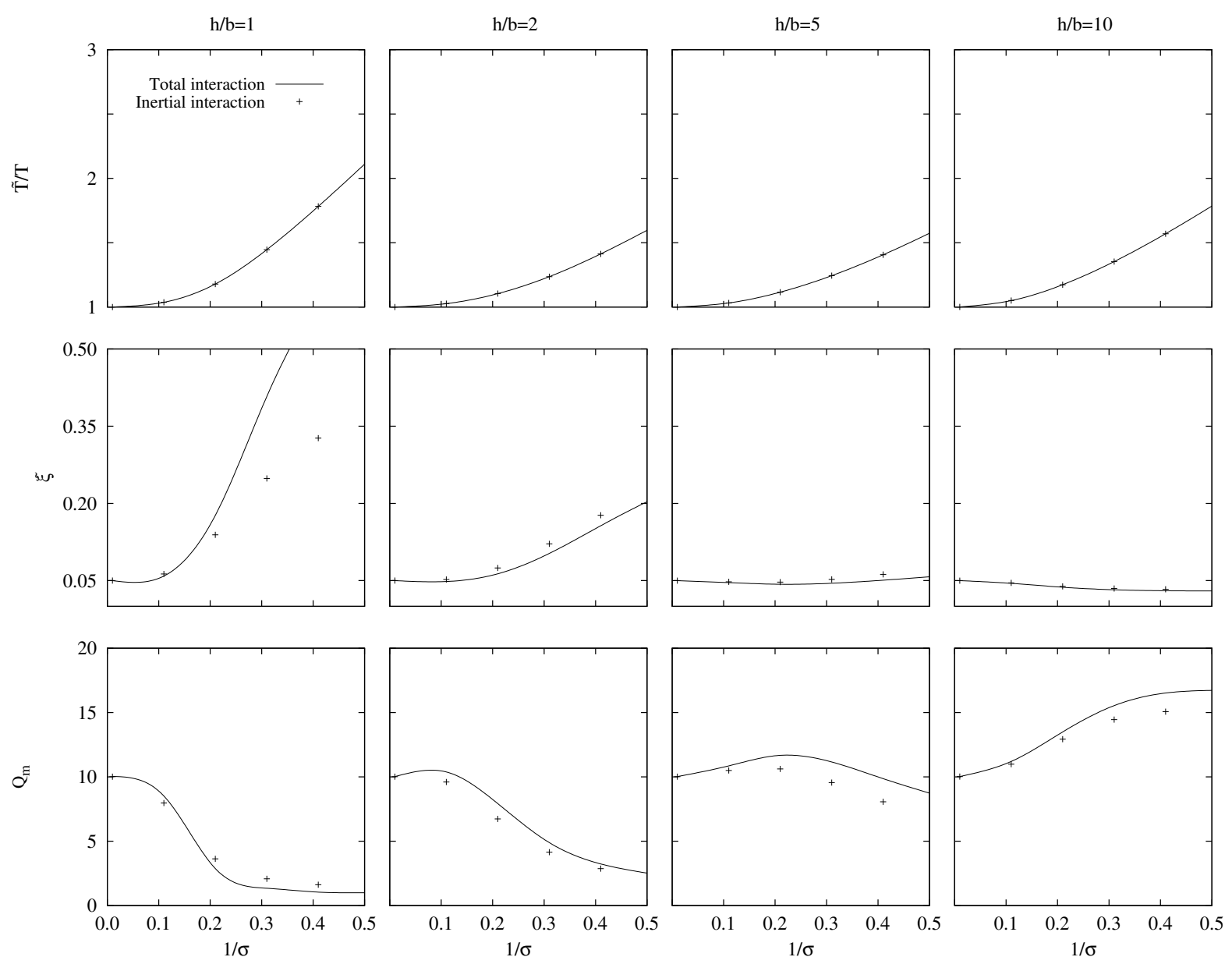

Figure 9: Effective period $\tilde{T} / T$, damping ratio $\tilde{\xi}$ and maximum structural response value $Q_{m}$ for $4 \times 4$ pile groups with $L / d=15, L / b=4$ and $\xi_{s}=0.05$. Influence of kinematic interaction factors

kinematic interaction effects into account are not on the side of safety except for non-slender structures $h / b \leq 1$, in which case this trend could be reversed.

\subsection{Influence of pile group size}

A decrease of the number of piles leads to a reduction of the system stiffness, which implies an increase of the effective period that becomes more remarkable for greater values of $h / b$, as it can be seen in Figure 10, Regarding the effective damping $\tilde{\xi}$, for $h / b \leq 2$, it reaches greater values as the number of piles increases which leads to smaller values of $Q_{m}$.

\section{CONCLUSIONS}

In this paper, several parametric analysis are presented in order to study the influence of SSI on the dynamic characteristics of structures founded on square pile groups, in homogeneous viscoelastic half-spaces subjected to vertically incident $S$ waves. The analysis is performed by a substructuring model in the frequency domain that takes into account both kinematic and inertial 

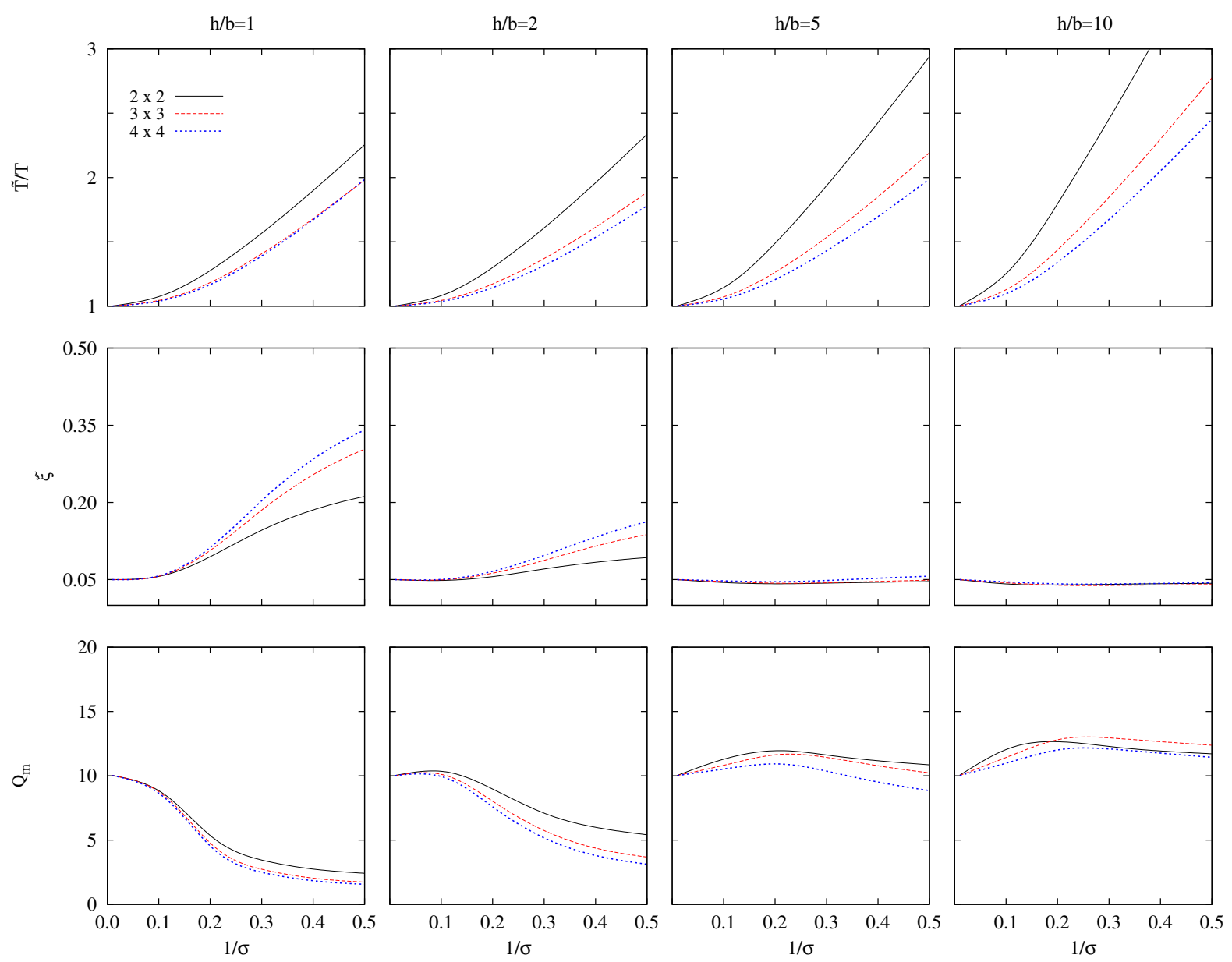

Figure 10: Effective period $\tilde{T} / T$, damping ratio $\tilde{\xi}$ and maximum structural response value $Q_{m}$ for pile groups with $L / d=15, L / b=2$ and $\xi_{s}=0.05$. Influence of pile group size 
interaction effects. In order to do this, a simplified, stable and accurate procedure is proposed herein. This procedure allows to determine the effective period and damping of an equivalent viscously damped single-degree-of-freedom (SDOF) oscillator, which being subjected to the free-field ground motion, causes the same response in terms of shear force at the base of the structure as the coupled system involving kinematic and inertial interaction with the foundation ground within the range where the peak response occurs.

All the results provided herein have a dimensionless character, thus their physical interpretation must be carefully done and requires a specific data processing taking into account the influence of every dimensionless parameter.

The main conclusions are summarised below.

- The kinematic interaction does not influence the system effective period but leads to lower values of the system damping, except for non-slender structures.

- Increasing values of the number of piles result in an increase of the foundation stiffness which leads to lower values of $\tilde{T} / T$ and greater values of $\tilde{\xi}$.

- In the same line, lower values of the pile-soil Young's modulus ratio $E_{p} / E_{s}$ result in an increase of the foundation stiffness which leads to lower values of the effective period and greater values of the effective damping.

- An increase of the mass density ratio implies greater values of the system effective period and damping.

- The effective period is not affected by variations of the fixed-base structure damping ratio $\xi$. However, the influence of this variation on the effective damping is more important as the wave parameter increases.

- For slender buildings, the system effective damping remains close to that corresponding to fixed-base condition or lower.

Soil-structure interaction effects significantly influences the system response. Period and damping curves have been obtained considering these effects and they show noticeable differences in relation to those obtained considering fixed-base condition. These effects are more decisive for pile foundations than for embedded or surface-supported foundations and its influence depends substantially on the configuration of the foundation.

\section{ACKNOWLEDGEMENTS}

This work was supported by the Ministerio de Investigación, Ciencia e Innovación of Spain (MICINN) and FEDER through research project BIA2010-21399-C02-01 and also by the Agencia Canaria de Investigación, Innovación y Sociedad de la Información (ACIISI) of the Government of the Canary Islands and FEDER through research project ProID20100224. C. Medina is a recipient of a fellowship from the Program of predoctoral fellowships of the University of Las Palmas de Gran Canaria (ULPGC). The authors are grateful for this support.

\section{APPENDIX}



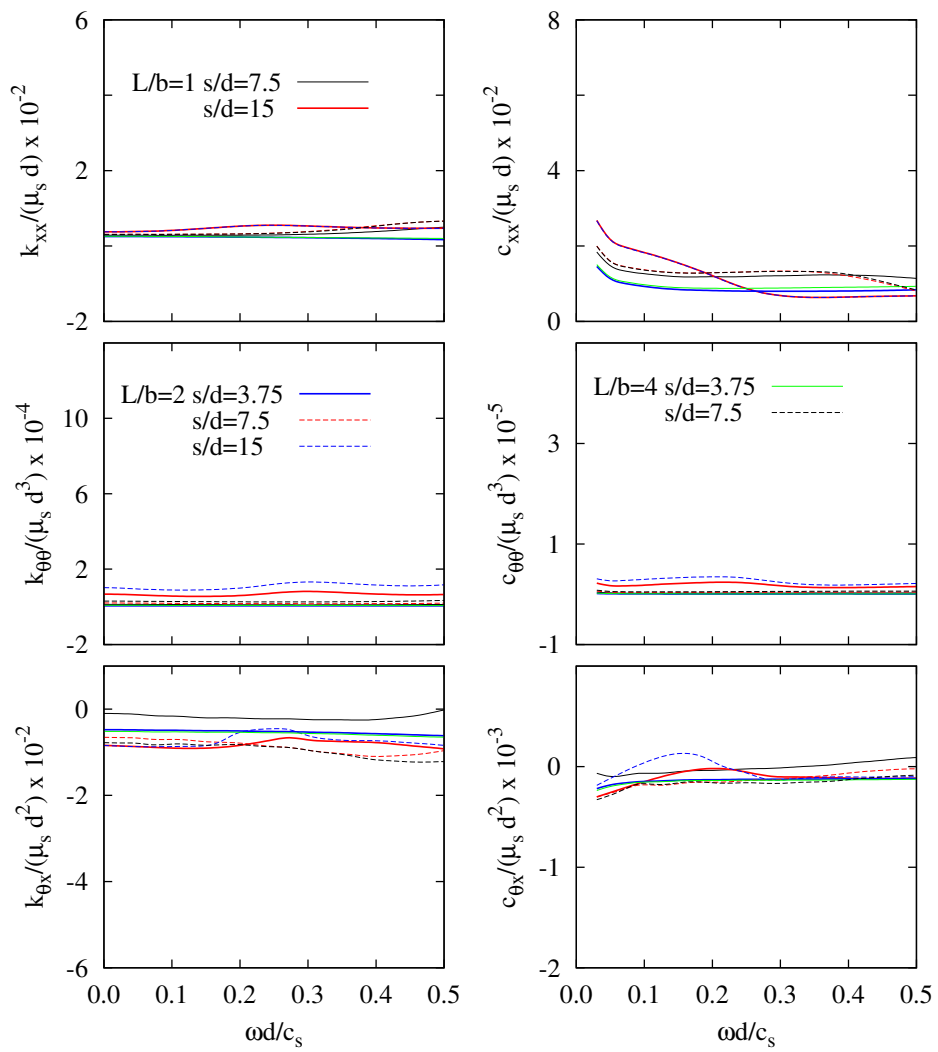

Figure 11: Impedance functions of different $2 \times 2$ pile groups; $E_{p} / E_{s}=10^{3}$ and $\xi_{s}=0.05$.
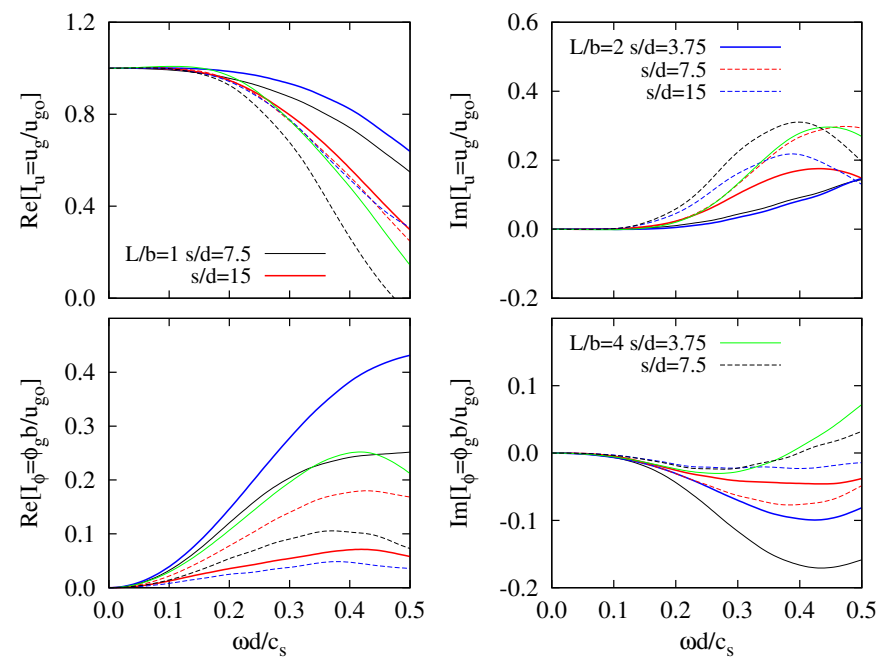

Figure 12: Kinematic interaction factors of different $2 \times 2$ pile groups; $E_{p} / E_{s}=10^{3}$ and $\xi_{s}=0.05$. 

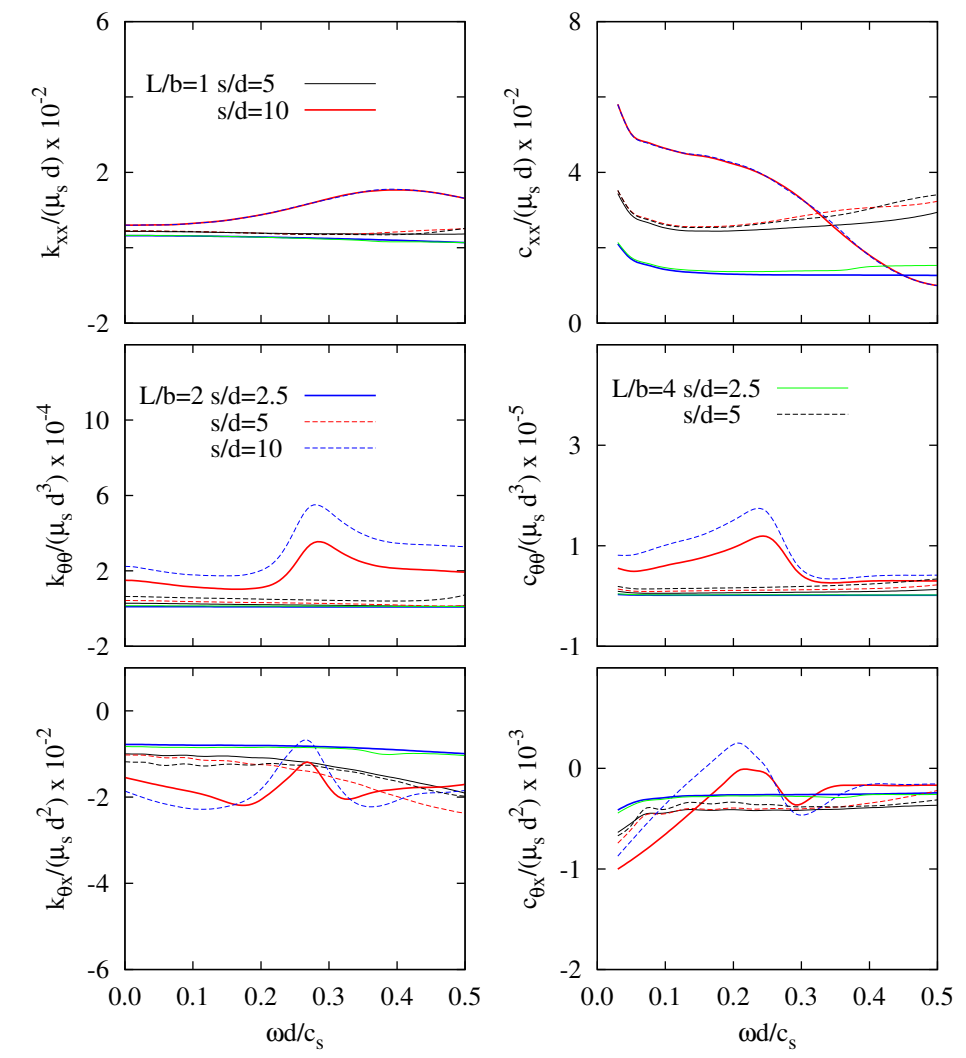

Figure 13: Impedance functions of different $3 \times 3$ pile groups; $E_{p} / E_{s}=10^{3}$ and $\xi_{s}=0.05$.
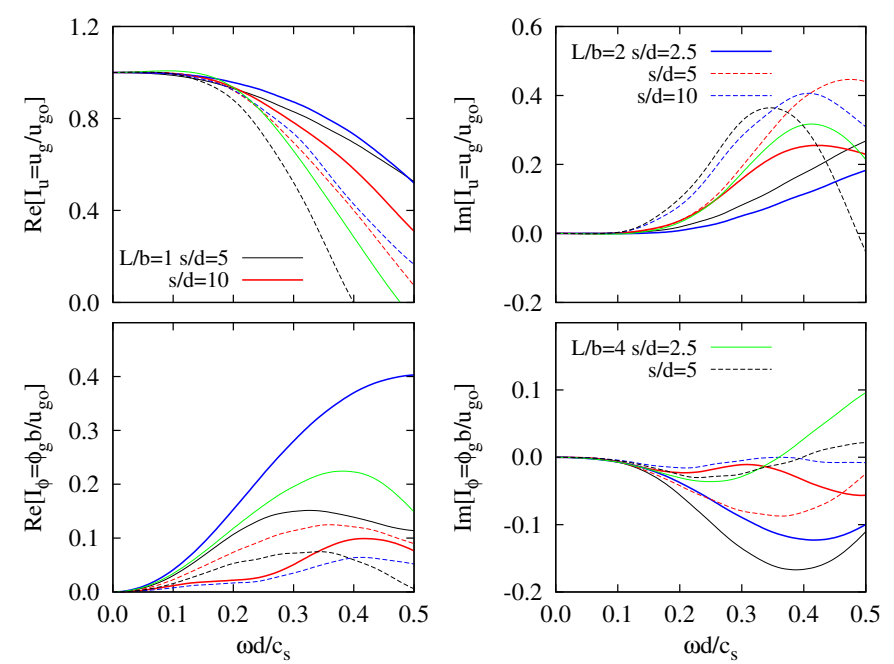

Figure 14: Kinematic interaction factors of different $3 \times 3$ pile groups; $E_{p} / E_{s}=10^{3}$ and $\xi_{s}=0.05$. 

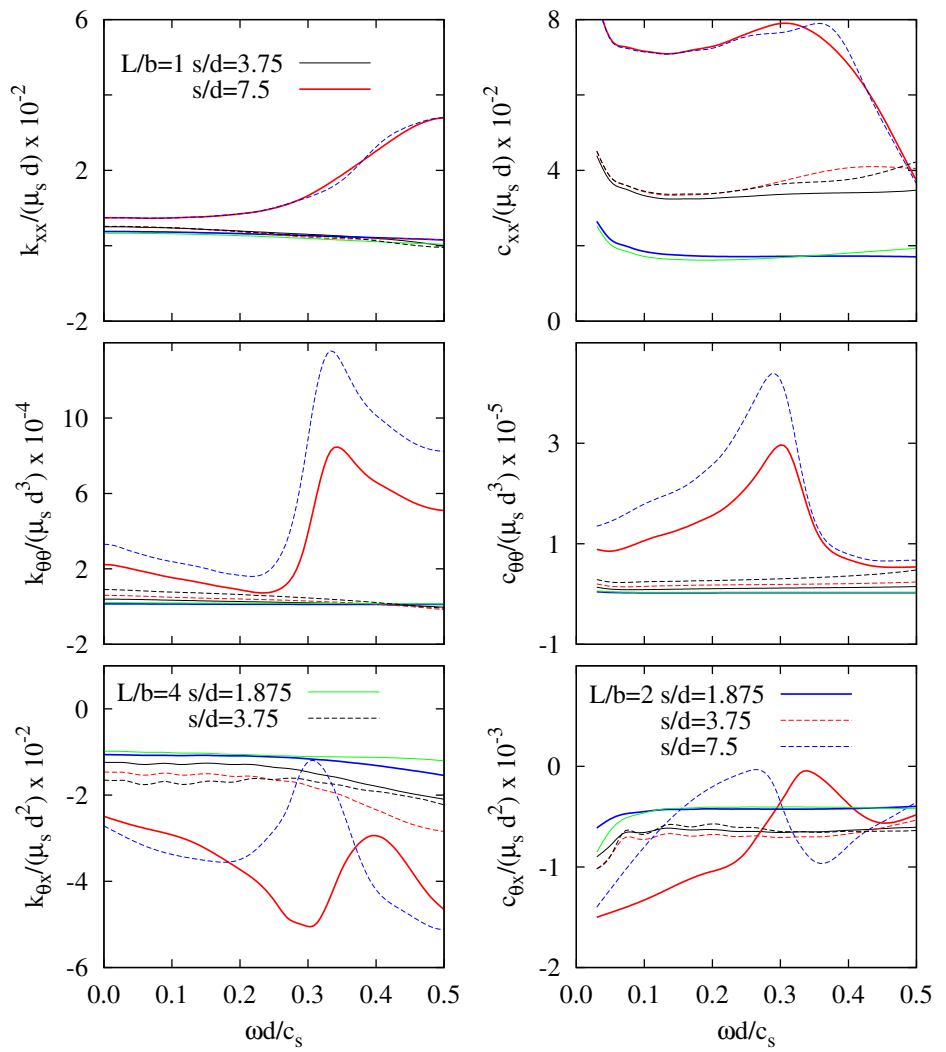

Figure 15: Impedance functions of different $4 \times 4$ pile groups; $E_{p} / E_{s}=10^{3}$ and $\xi_{s}=0.05$.
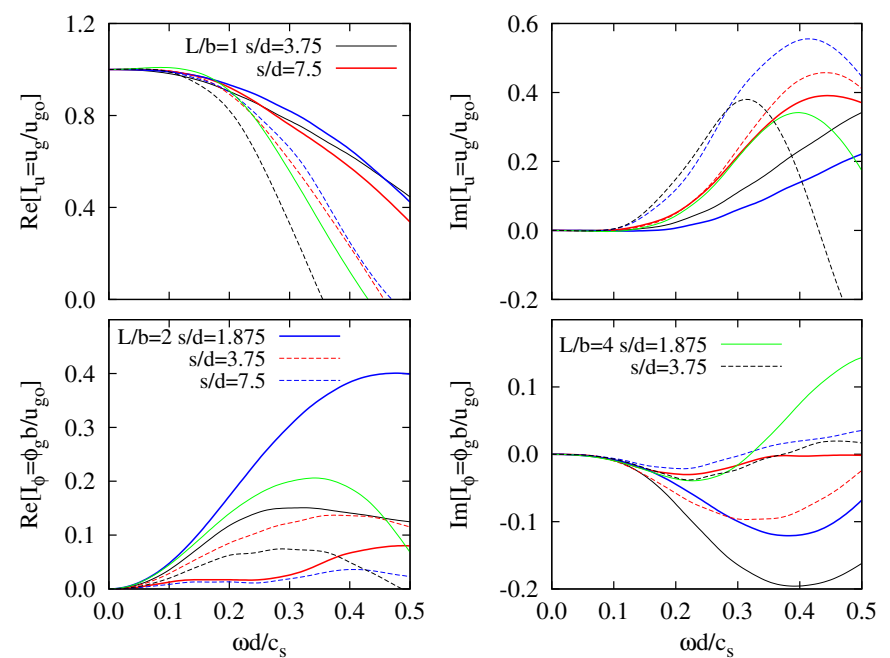

Figure 16: Kinematic interaction factors of different $4 \times 4$ pile groups; $E_{p} / E_{s}=10^{3}$ and $\xi_{s}=0.05$. 

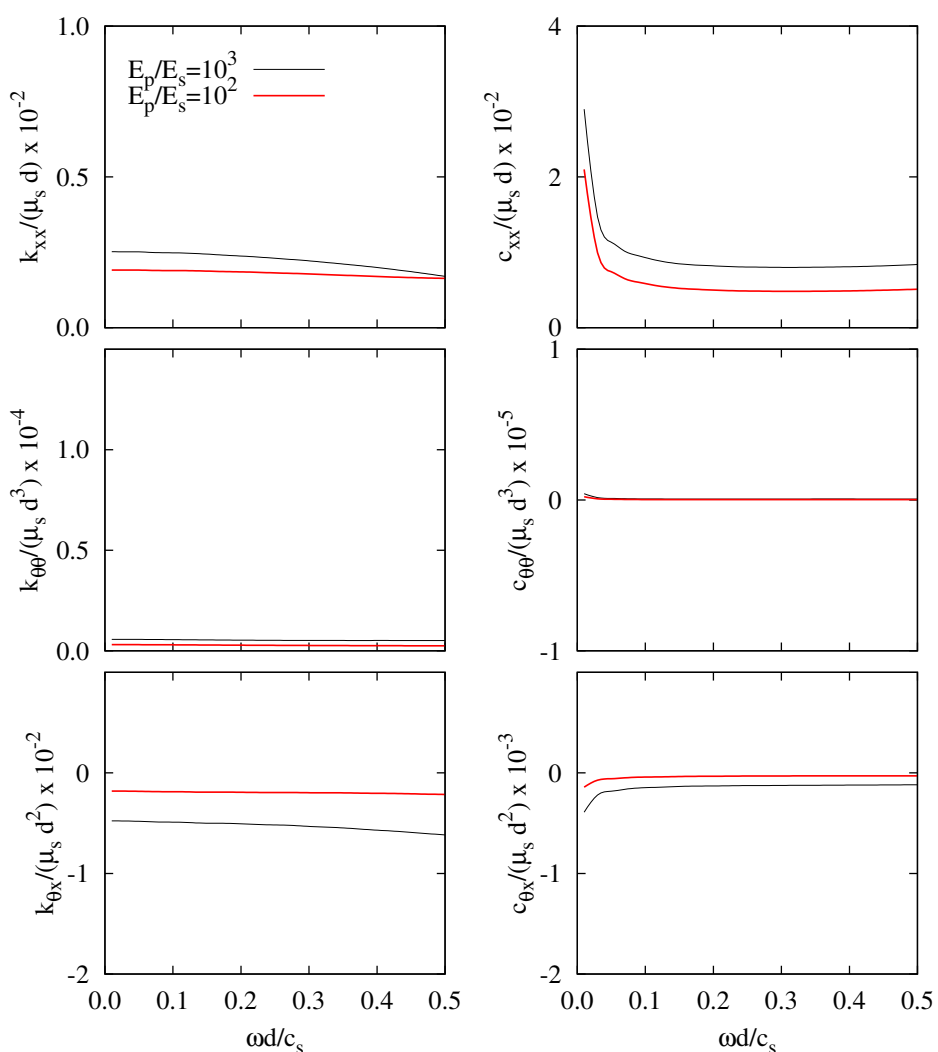

Figure 17: Impedance functions for a $2 \times 2$ pile group with $L / d=7.5, L / b=2$ and $\xi_{s}=0.05$. Influence of the pile-soil Young's modulus ratio $E_{p} / E_{s}$
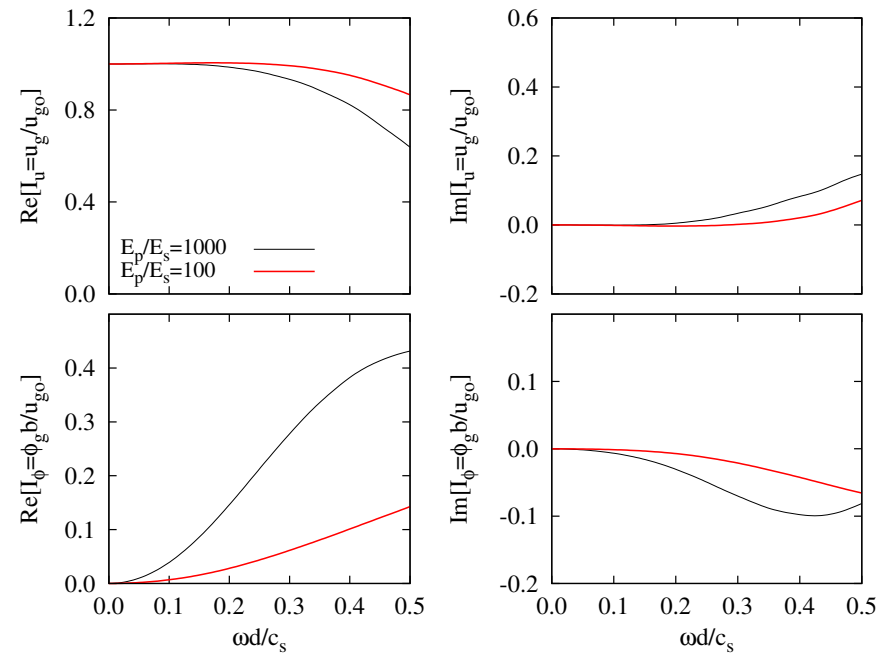

Figure 18: Kinematic interaction factors for a $2 \times 2$ pile group with $L / d=7.5, L / b=2$ and $\xi_{s}=0.05$. Influence of the pile-soil Young's modulus ratio $E_{p} / E_{s}$ 

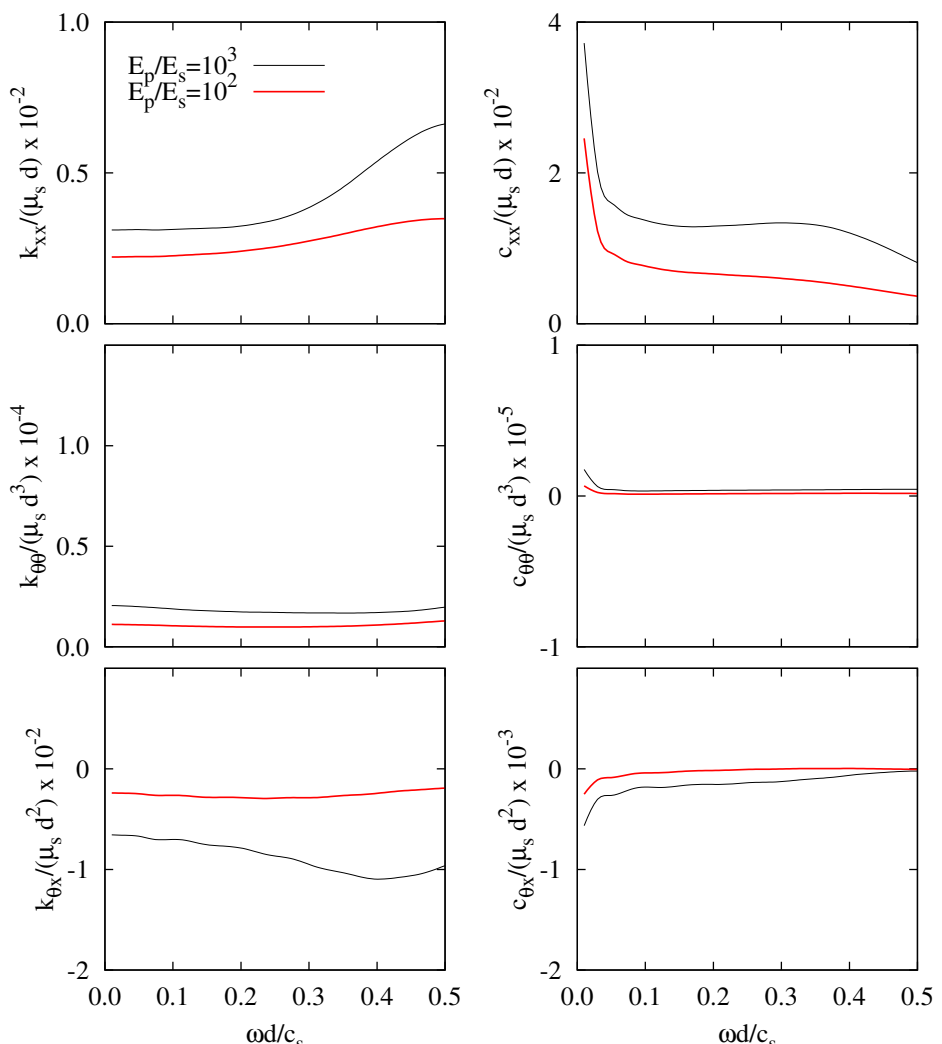

Figure 19: Impedance functions for a $2 \times 2$ pile group with $L / d=15, L / b=2$ and $\xi_{s}=0.05$. Influence of the pile-soil Young's modulus ratio $E_{p} / E_{s}$
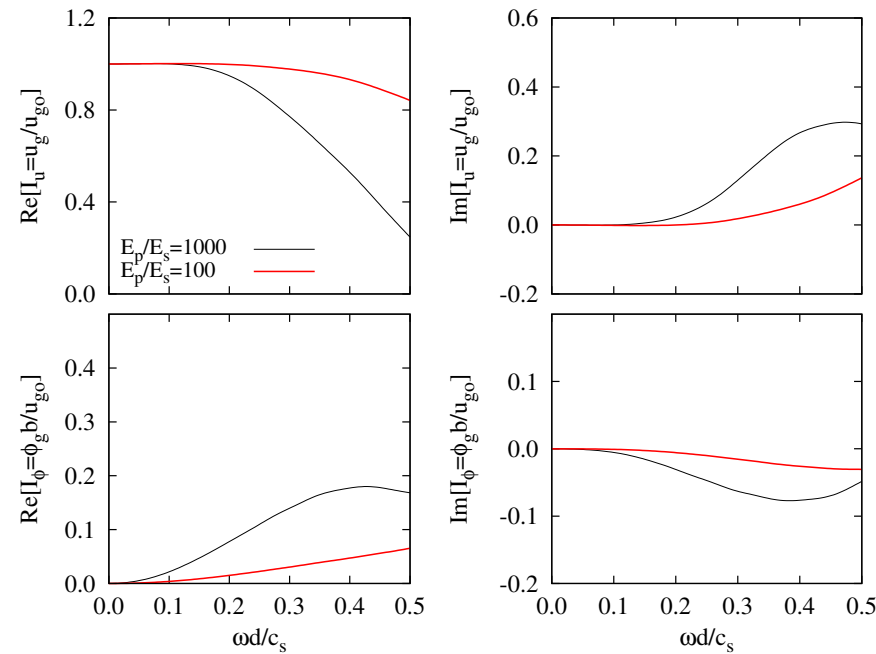

Figure 20: Kinematic interaction factors for a $2 \times 2$ pile group with $L / d=15, L / b=2$ and $\xi_{s}=0.05$. Influence of the pile-soil Young's modulus ratio $E_{p} / E_{s}$ 

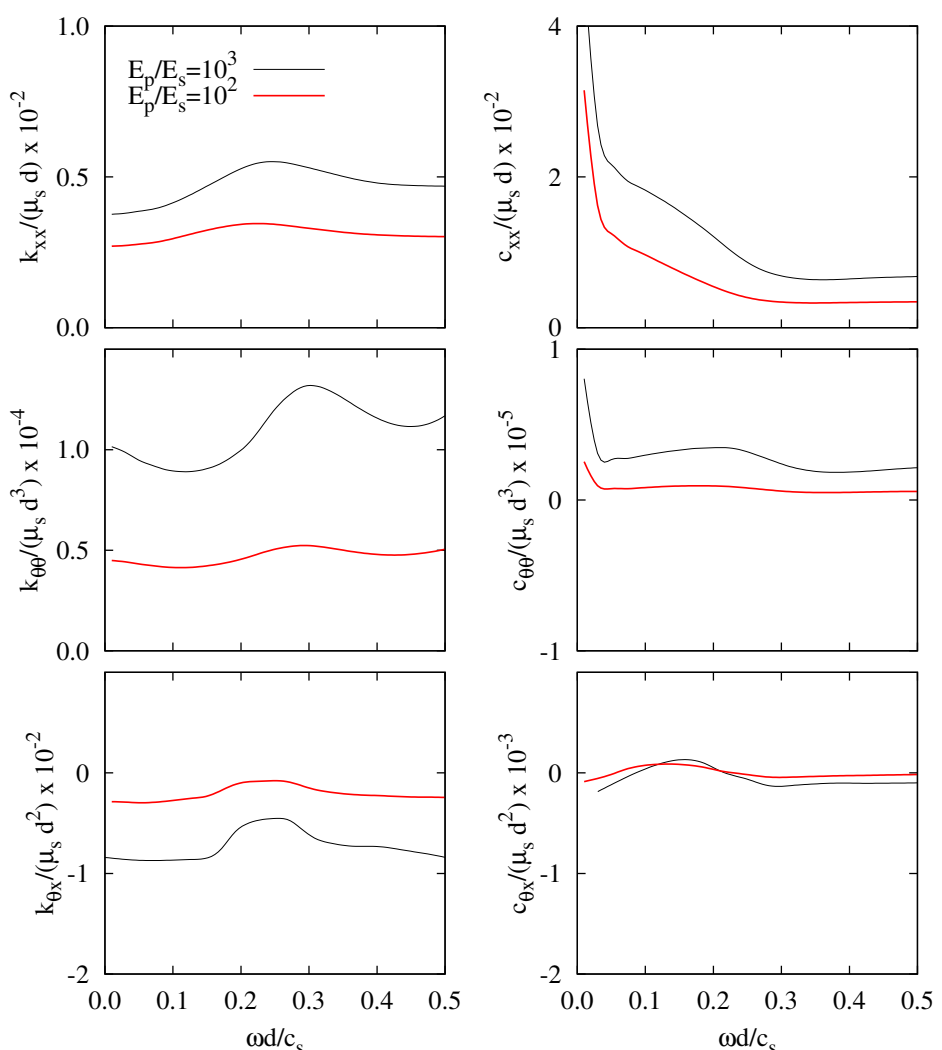

Figure 21: Impedance functions for a $2 \times 2$ pile group with $L / d=30, L / b=2$ and $\xi_{s}=0.05$. Influence of the pile-soil Young's modulus ratio $E_{p} / E_{s}$
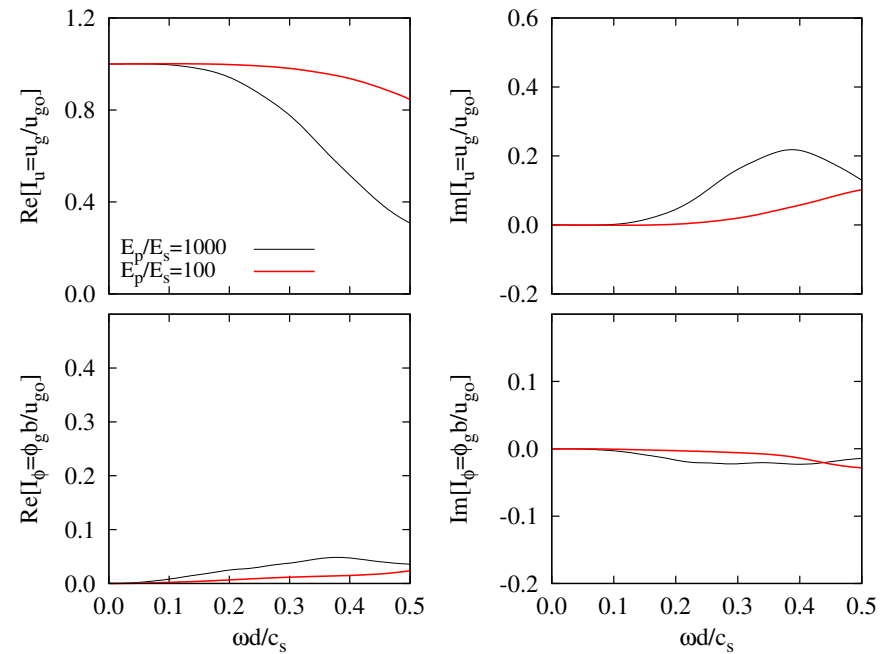

Figure 22: Kinematic interaction factors for a $2 \times 2$ pile group with $L / d=30, L / b=2$ and $\xi_{s}=0.05$. Influence of the pile-soil Young's modulus ratio $E_{p} / E_{s}$ 


\section{REFERENCES}

[1] J. Guin, P. K. Banerjee, Coupled soil-pile-structure interaction analysis under seismic excitation, J Struct Eng, 124, 434-444, 1998.

[2] K. K. Koo, K. T. Chau, X. Yang, S. S. Lam, Y. L. Wong, Soil-pile-structure interaction under SH wave excitation, Earthquake Eng Struct Dyn, 32, 395-415, 2003.

[3] M. A. Millán, J. Domínguez, Simplified BEM/FEM model for dynamic analysis of structures on piles and pile groups in viscoelastic and poroelastic soils, Eng Anal Bound Elem, 33, 25-34, 2009.

[4] L. A. Padrón, J. J. Aznárez, O. Maeso, Dynamic structure-soil-structure interaction between nearby piled buildings under seismic excitation by BEM-FEM model, Soil Dyn Earthquake Eng, 29, 1084-1096, 2009.

[5] L. A. Padrón, J. J. Aznárez, O. Maeso, 3-D boundary element - finite element method for the dynamic analysis of piled buildings, Eng Anal Bound Elem, 35, 465-477, 2011.

[6] P. C. Jennings, J. Bielak, Dynamics of building-soil interaction, Bull Seismol Soc Am, 63, 9-48, 1973.

[7] A. S. Veletsos, J. W. Meek, Dynamic behaviour of building-foundation systems, Earthquake Engng Struct Dyn, 3, 121-138, 1974.

[8] A. S. Veletsos, V. V. D. Nair, Seismic interaction of structures on hysteretic foundations, $J$ Struct Div, ASCE, 101, 109-129, 1975.

[9] J. Bielak, Modal analysis for building-soil interaction, J Engng Mech Div ASCE, 102, 771-786, 1976.

[10] J. E. Luco, Linear soil-structure interaction, Technical Report UCRL-15272, Lawrence Livermore National Laboratory, Livermore, California, 1980.

[11] J. E. Luco, Soil-structure interaction and identification of structural models, in: Proc. ASCE Speciality Conf. in Civil Engineering and Nuclear Power, Knoxville, Tennessee, 1980.

[12] J. P. Wolf, Dynamic soil-structure interaction, Englewood Cliffs, (NJ); Prentice-Hall, 1985.

[13] J. Avilés, L. E. Pérez-Rocha, Evaluation of interaction effects on the system period and the system damping due to foundation embedment and layer depth, Soil Dyn Earthquake Engng, 15, 11-27, 1996.

[14] J. Bielak, Dynamic behaviour of structures with embedded foundations, Earthquake Engng Struct Dyn, 3, 259-274, 1975.

[15] J. Avilés, L. E. Pérez-Rocha, Effects of foundation embedment during building-soil interaction, Earthquake Engng Struct Dyn, 27, 1523-1540, 1998. 
[16] A. Maravas, G. Mylonakis, D. Karabalis, Dynamic characteristics of simple structures on piles and footings, in: Proc. of 4th Int Conf on Earthquake Geotech Eng, no. 1672, Thessaloniki, Greece.

[17] E. Kausel, J. M. Roësset, Soil-structure interaction for nuclear containment, in: Electric Power and Civil Engineer. Power Div. ASCE Specialty Conf, Boulder, Colorado, pp. 469498, 1974.

[18] E. Kausel, Structures in seismic regions, Technical Report, Technische universitt Berlin and MIT, 1984.

[19] A. K. Chopra, Dynamic of structures. Theory and applications to earthquake engineering., Prentice-Hall (NJ), 2001.

[20] G. Gazetas, K. Fan, T. Tazoh, K. Shimizu, M. Kavvadas, N. Makris, Seismic pilegroupstructure interaction, Geothec Spec Publ, ASCE, 34, 56-93, 1992.

[21] K. Fan, G. Gazetas, A. M. Kaynia, E. Kausel, S. Ahmad, Kinematic seismic response of single piles and pile groups, J Geothec Eng Div, ASCE, 117(12), 1860-1879, 1991.

[22] S. Nikolaou, G. Mylonakis, G. Gazetas, T. Tazoh, Kinematic pile bending during earthquakes: Analysis and field measurements, Géothecnique, 51(5), 425-440, 2001. 